\title{
LaSRC (Land Surface Reflectance Code): Overview, application and validation using MODIS, VIIRS, LANDSAT and Sentinel 2 data's
}

\author{
E. Vermote ${ }^{1}$, J.C. Roger ${ }^{2,1}$, B. Franch ${ }^{2,1}$, Sergii Skakun ${ }^{2,1}$ \\ ${ }^{1}$ NASA Goddard Space Flight Center, Code 619, Greenbelt, MD 20771, United States \\ ${ }^{2}$ Department of Geographical Sciences, University of Maryland, College Park MD 20742, United States
}

\begin{abstract}
This paper presents a generic approach developed to derive surface reflectance over land from a variety of sensors. This technique builds on the extensive dataset acquired by the Terra platform by combining MODIS and MISR to derive an explicit and dynamic map of band ratio's between blue and red channels and is a refinement of the operational approach used for MODIS and LANDSAT over the past 15 years. We will present the generic approach and the application to MODIS VIIRS, LANDSAT and Sentinel 2 data's and its validation using the AERONET data [1].
\end{abstract}

Index Terms — surface reflectance, aerosol, validation.

\section{INTRODUCTION}

The spectral bidirectional surface reflectance, i.e., satellite derived top-of-atmosphere (TOA) reflectance corrected for the temporally, spatially and spectrally varying scattering and absorbing effects of atmospheric gases and aerosols, is needed to monitor the land surface reliably. For this reason, the spectral bidirectional surface reflectance, and not TOA reflectance, is used to generate the greater majority of the global land products for example from the MODIS and VIIRS sensors. Even if atmospheric effects are minimized by sensor design, the impacts of aerosols can be difficult to correct because they can be highly discrete in space and time (e.g., smoke plumes) and because of the complex scattering and absorbing properties of aerosols that vary spectrally and with aerosol size, shape, chemistry and density.

We will first present the physically based inversion of surface reflectance based on rigorous radiative transfer (2.1), then give an overview of the generic approach for aerosol inversion over land applicable to any sensor that has at least one red and blue band (2.2), then we will show some validation results using this approach for VIIRS, LANDSAT and Sentinel 2 data's and comparison of performances to precursor algorithms (3.).

\section{METHODOLOGY}

\subsection{Surface reflectance inversion}

The method adopted for atmospheric correction relies on the inversion of the relatively simple equation in the Lambertian case, with no adjacency effects that account for a simplified coupling of the absorption by atmospheric gases and scattering by molecules and aerosols as it is implemented in the $6 \mathrm{SV}$ radiative transfer code $[2,3]$ :

$\rho_{\mathrm{TOA}}(\theta_{\mathrm{s}}, \theta_{\mathrm{v}}, \phi, \mathrm{P}, \overbrace{\tau_{\mathrm{A}}, \omega_{0}, \mathrm{P}_{\mathrm{A}}}^{\text {Aer }}, \mathrm{U}_{\mathrm{H}_{2} \mathrm{O}}, \mathrm{U}_{\mathrm{O}_{3}})=\operatorname{Tg}_{\mathrm{OG}}(\mathrm{m}, \mathrm{P}) \operatorname{Tg}_{\mathrm{O}_{3}}\left(\mathrm{~m}, \mathrm{U}_{\mathrm{U}_{\mathrm{O}_{3}}}\right)$

$$
\begin{aligned}
& \mathrm{x} \\
& \left\{\begin{array}{l}
\rho_{\mathrm{atm}}\left(\theta_{\mathrm{s}}, \theta_{\mathrm{v}}, \phi, \mathrm{P}, \text { Aer, } \mathrm{U}_{\mathrm{H}_{2} \mathrm{O}}\right)+ \\
\operatorname{Tr}_{\mathrm{atm}}\left(\theta_{\mathrm{s}}, \theta_{\mathrm{v}}, \mathrm{P}, \text { Aer }\right) \frac{\rho_{\mathrm{s}}}{1-\mathrm{S}_{\mathrm{atm}}(\mathrm{P}, \operatorname{Aer}) \rho_{\mathrm{s}}} \operatorname{Tg}_{\mathrm{H}_{2} \mathrm{O}}\left(\mathrm{m}, \mathrm{U}_{\mathrm{U}_{\mathrm{H}_{2} \mathrm{O}} \mathrm{O}}\right)
\end{array}\right]
\end{aligned}
$$

where

$\rho_{\mathrm{TOA}}$ is the reflectance at the top of the atmosphere, $\rho_{\mathrm{atm}}$ is the atmosphere intrinsic reflectance, $\operatorname{Tr}_{\text {atm }}$ is the total atmosphere transmission (downward and upward), $\mathrm{S}_{\text {atm }}$ is the atmosphere spherical albedo, and $\rho_{\mathrm{s}}$ is the surface reflectance to be retrieved by the atmospheric correction procedure:

the geometrical conditions are described by the solar zenith angle $\theta_{\mathrm{s}}$, the view zenith angle $\theta_{\mathrm{v}}$, and the relative azimuth $\phi$ (or the difference between the solar and view azimuth angles);

$\mathrm{P}$ is the pressure that influences the number of molecules and the concentration of absorbing gases in the atmosphere, $\mathrm{Tg}$ designates the gaseous transmission by water vapor $\left(\mathrm{Tg}_{\mathrm{H}_{2} \mathrm{O}}\right)$, ozone $\left(\mathrm{Tg}_{\mathrm{O}_{3}}\right)$, or other gases $\left(\mathrm{Tg}_{\mathrm{OG}}\right), \mathrm{U}_{\mathrm{H}_{2} \mathrm{O}}$ is the integrated water vapor content, $\mathrm{U}_{\mathrm{O}_{3}}$ is the integrated ozone content, and $\mathrm{m}$ is the so-called "air-mass" computed as $1 / \cos \left(\theta_{\mathrm{s}}\right)+1 / \cos \left(\theta_{\mathrm{v}}\right)$;

$\tau_{\mathrm{A}}, \omega_{0}$ and $\mathrm{P}_{\mathrm{A}}$ describe the aerosol properties and are spectrally dependent: $\tau_{\mathrm{a}}$ is the aerosol optical thickness, $\omega_{0}$ is the aerosol single scattering albedo, and $\mathrm{P}_{\mathrm{A}}$ is the aerosol phase function. 
The effect of water vapor on the atmosphere intrinsic reflectance can be approximated as:

$\rho_{\mathrm{atm}}\left(\theta_{\mathrm{s}}, \theta_{\mathrm{v}}, \phi, \mathrm{P}\right.$, Aer, $\left.\mathrm{U}_{\mathrm{H}_{2} \mathrm{O}}\right)=\rho_{\mathrm{R}}\left(\theta_{\mathrm{s}}, \theta_{\mathrm{v}}, \phi, \mathrm{P}\right)+$

$\left(\rho_{\mathrm{R}+\text { Aer }}\left(\theta_{\mathrm{s}}, \theta_{\mathrm{v}}, \phi, \mathrm{P}\right.\right.$, Aer $\left.)-\rho_{\mathrm{R}}\left(\theta_{\mathrm{s}}, \theta_{\mathrm{v}}, \phi, \mathrm{P}\right)\right) \operatorname{Tg}_{\mathrm{H}_{2} \mathrm{O}}\left(\mathrm{m}, \frac{\mathrm{U}_{\mathrm{U}_{\mathrm{H}_{2} \mathrm{O}}}}{2}\right)$

where $\rho_{R}$ represents the reflectance of the atmosphere due to molecular (Rayleigh) scattering and $\rho_{\mathrm{R}+\mathrm{Aer}}$ represents the reflectance of the mixture of molecules and aerosol particles. Accounting correctly for the mixing and the socalled coupling effect [2] is important for achieving a high accuracy of atmospheric effect modeling. This approximation conserves the correct computation of the coupling and assumes that water vapor is mixed with aerosol particles and that molecular scattering is not affected by water vapor absorption.

As the scheme of the atmospheric correction is relatively simple in terms of input and inversion (see Equation [1]), and its operational implementation is relatively straightforward, the challenge lies in estimating the atmospheric parameters of Equation [1] and [2].

The atmospheric pressure $\mathbf{P}$ is obtained from a combination of a coarse-resolution (one deg., six hours time step) weather prediction model available from NCEP GDAS (2015) sea level pressure $P_{\mathrm{sl}}$ and the altitude $\mathbf{z}[\mathrm{km}]$ given by a Digital Elevation Model at 0.05 degree resolution (ETOPO5, 1988).

The ozone amount UO3 is also obtained via NCEP GDAS (2015) (at 1deg., 6 hours time step) The water vapor is extracted from the ancillary information included in the MODIS surface reflectance Climate Modeling Grid (MOD09CMA) for Terra which is itself computed from the MODIS near-infrared band 18 (931-941 nm) and 19 (915$965 \mathrm{~nm})$ at $1 \mathrm{~km}$ spatial resolution [4].

The aerosol characteristics $\left(\tau_{\mathrm{A}}, \omega_{0}\right.$ and $\left.\mathrm{P}_{\mathrm{A}}\right)$ pose a greater challenge. The inversion scheme is adapted from the Collection 6 MODIS surface reflectance algorithm, which is based on the Collection 5 algorithm that stems from the work of (Kaufman et al., 1997). The basic principle of this method was to use an a-priori relationship between the reflectance observed in the middle infra-red (mid-IR) $(2.1 \mu \mathrm{m})$ and the blue $(0.47 \mu \mathrm{m})$ and Red $(0.66 \mu \mathrm{m})$ bands of MODIS to constrain the inversion. That relationship is connected by the fact that the vegetation liquid water content that influences the signal in the mid-IR is related to the photosynthetic activity that absorbs the radiation in the blue and red. However, both the MODIS aerosol group [6], and the MODIS surface reflectance group [7,8] found that there was a stronger relationship between red and blue MODIS band than blue and mid-Ir. Consequently, the approach proposed here use the relationship between the blue and red band to invert AOT.

\subsection{Aerosol inversion}

The method for inverting the AOT from is relatively simple if the ratio between the red and blue bands can be known for every pixel. This ratio was computed at coarse resolution (0.05 degree) from 10 years of MODIS (Terra) and MISR data (see Figure 2). The MISR AOT product was used as input to the atmospheric correction of the MODIS TOA data for each valid observation providing the MODIS surface reflectances that was used to derive a ratio at 0.05 degree, the data are carefully filtered for clouds and high AOT values.

This data processing enables to account for the accuracy of that ratio globally and across several years and seasons. The ratio was computed for each valid observation and subsequently fitted as a linear function of $\mathrm{NDVI}_{\mathrm{MIR}}$, a vegetation index that uses the Mid-IR $(2.1 \mu \mathrm{m})$ channel instead of Red:

$N D V I_{M I R}=\frac{N I R-M i d I R / 2}{N I R+M i d I R / 2}$

The advantage of this index being that it is much less sensitive to aerosol because of the use of Mid-IR in lieu of red but still close to the original NDVI as the Mid-IR and red ratio is around 0.5 over most surfaces (See [6]).

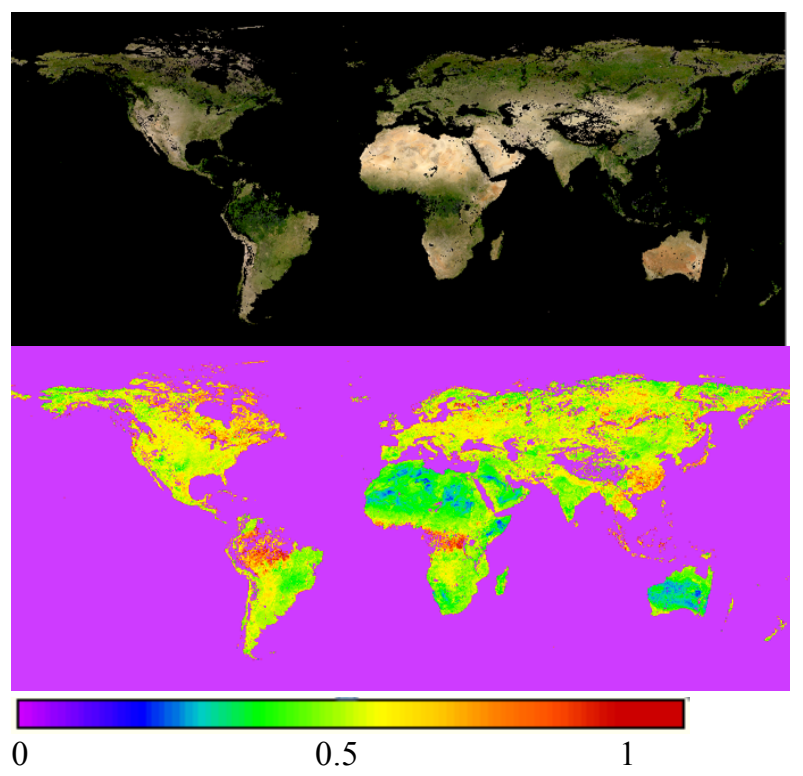

Figure 1: The upper panel shows the true color image, the lower one is the ratio blue (band 3)/red. Most of the values over vegetated areas fall around 0.5 which is close to the fixed value actually used in the original version of the aerosol retrieval algorithm. Over dense forest, the value of the ratio is higher, around 1. Over bare surfaces, the ratio is lower (between 0.5 and 0.25 ) and enables retrieval of the aerosol over this type of surfaces especially by using the other short wavelenght bands available on MODIS (band 8 at $412 \mathrm{~nm}$, band 9 at $443 \mathrm{~nm}$ and band 10 at $490 \mathrm{~nm}$ ). 
Second, this parameterization of the ratio as a function of $\mathrm{NDVI}_{\mathrm{MIR}}$ at the CMG level in addition to capturing the potential seasonal/annual variability of the ratio, enables to scale down this quantity to the spatial resolution of targeted instrument (VIIRS, MODIS at $1 \mathrm{~km}$ or Landsat at $30 \mathrm{~m}$ ) and use it in the retrieval of AOT at the pixel level

\section{RESULTS/VALIDATION}

Key steps in developing a science quality, long-term dataset are establishing the pre and post-launch uncertainty estimates and validating the product. In addition to tracking the calibration of the sensor, which is seminal to the atmospheric correction, the current approach relied first on the validation of the radiative transfer approach $[3,9,10]$, validating the $6 \mathrm{SV}$ code by inter-comparison with other codes, including the unambiguous Monte Carlo approach ([3] which shows $6 \mathrm{SV}$ to agree within $0.4 \%$ of the Monte Carlo results, http://rtcodes.ltdri.org/) and the application of the radiative transfer code over sites with detailed descriptions of the atmospheric properties from the AERONET [1]. This allowed to retrieve very accurate reflectance standards, such as measurements of water reflectance from MOBY off the coast of Lanai Island, Hawaii [3]. Once the radiative transfer approach is established, a practical means of validation is to establish a reference dataset based on the best possible atmospheric correction of the data of interest. In practice, the full radiative transfer code, $6 \mathrm{SV}$, is used and not the look up tables and parameterization of the gaseous transmission used in the operational surface reflectance product. The best possible source of water vapor and aerosol information is used as input to the code, which is achieved whenever two valid AERONET observations that bracket the MODIS data within $15 \mathrm{mins}$ can be obtained. This reference dataset can then be used to determine the accuracy, precision and uncertainty (APU) of the surface reflectance product originally defined by the National Polar-Orbiting Operational Environmental Satellite System (NPOESS) project to evaluate a variety of Earth Data Records (EDR) and are computed as follows:

$$
A=\frac{\sum_{i=1}^{N}\left(\mu_{i}^{e}-\mu_{i}^{t}\right)}{N} \quad P^{2}=\frac{\sum_{i=1}^{N}\left(\mu_{i}^{e}-\mu_{i}^{t}-A\right)^{2}}{N-1} U^{2}=\frac{\sum_{i=1}^{N}\left(\mu_{i}^{e}-\mu_{i}^{t}\right)^{2}}{N}
$$

Where in this case, $\mu^{\mathrm{e}}$ is the operational surface reflectance and $\mu^{t}$ is the surface reflectance truth.

Figure 2a-f, summarize the evaluation of this algorithm implemented in MODIS collection 6 and LANDSAT/OLI, it clearly shows improved performances compared to its precursor (MODIS collection 5 and LEDAPS). It also shows very consistent performances for Sentinel 2 and VIIRS.

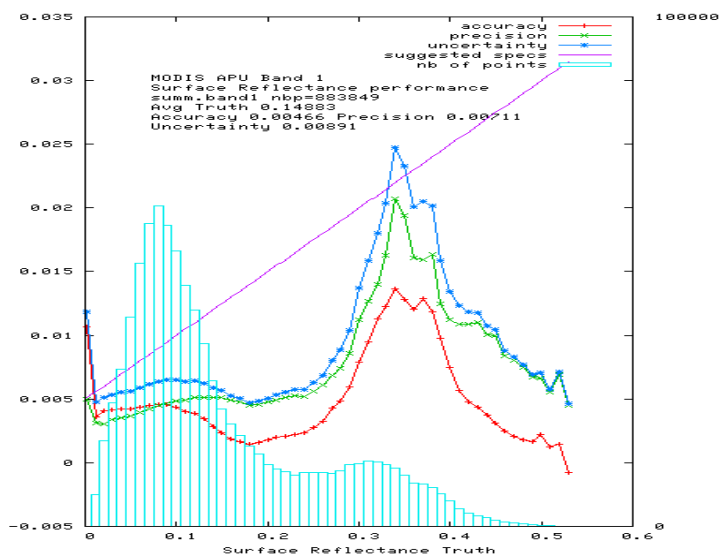

Figure 2a: APU for the MODIS red band, Collection 5.

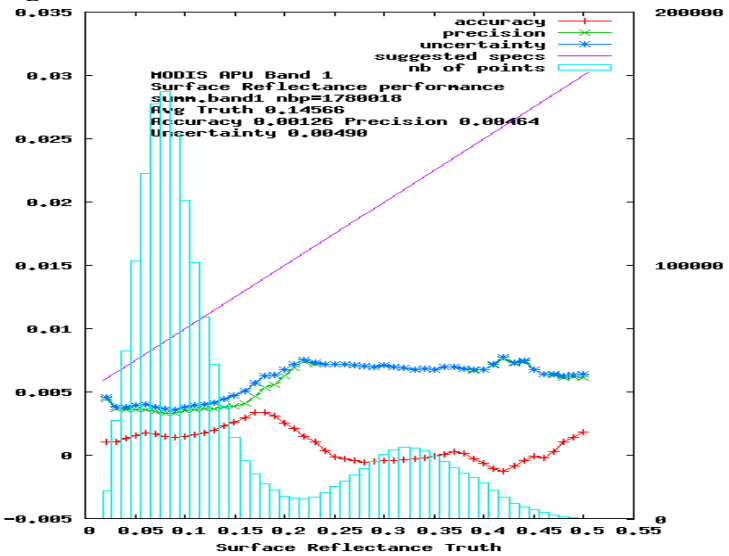

Figure 2b: Same as 2a but for Collection 6 (LaSRC)

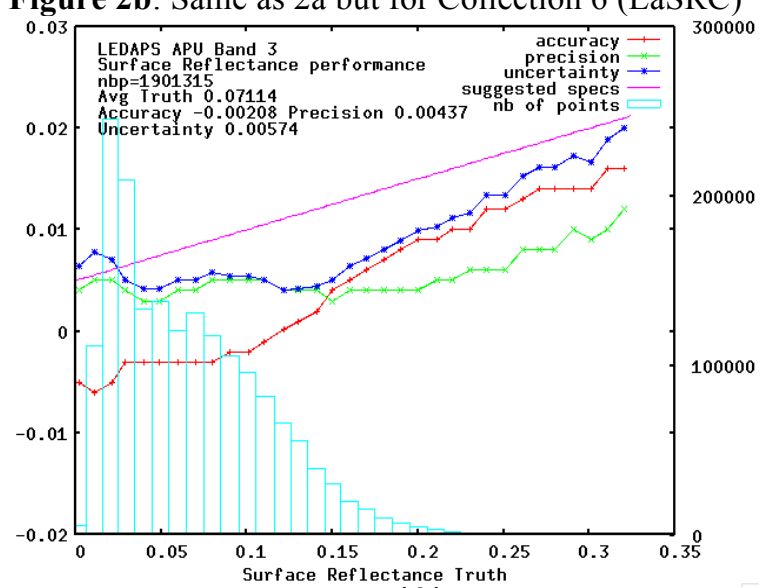

Figure 2c: same as 2a but for LANDSAT/ETM+, LEDAPS. 


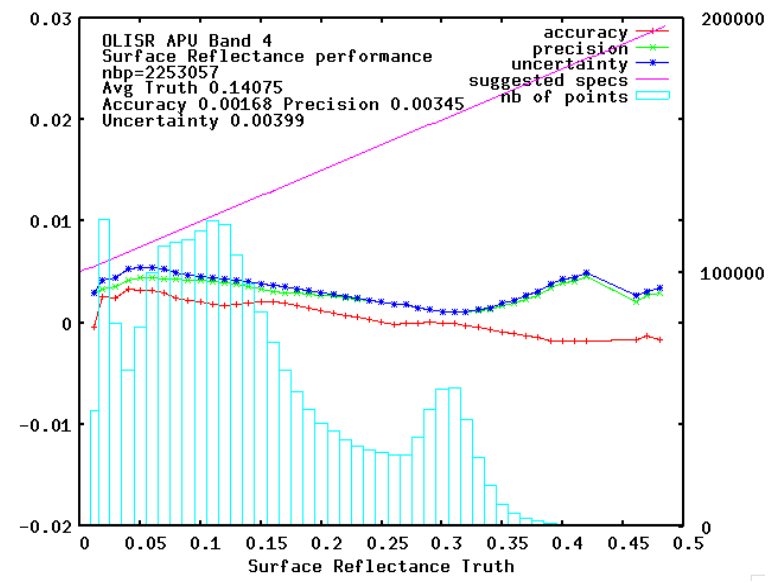

Figure 2d: same as 2a but for LANDSAT/OLI (LaSRC).

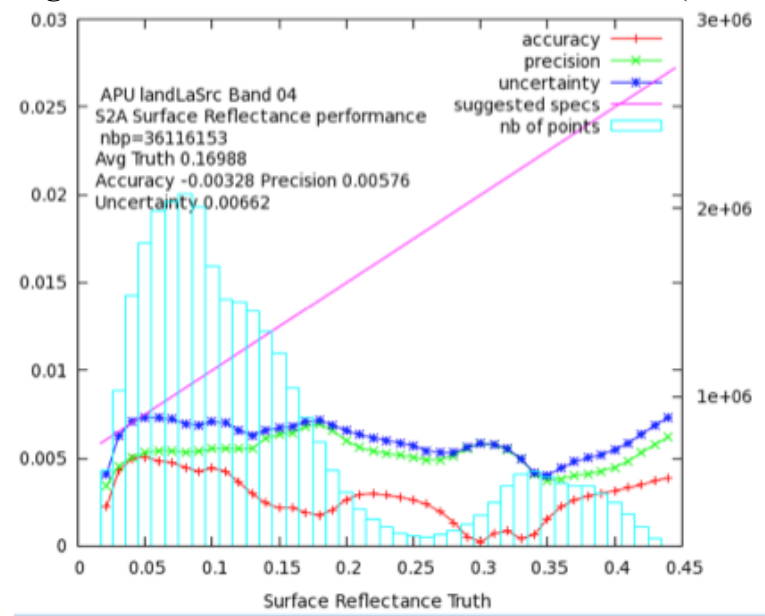

Figure 2e: same as 2a but for Sentinel 2/MSI (LaSRC).

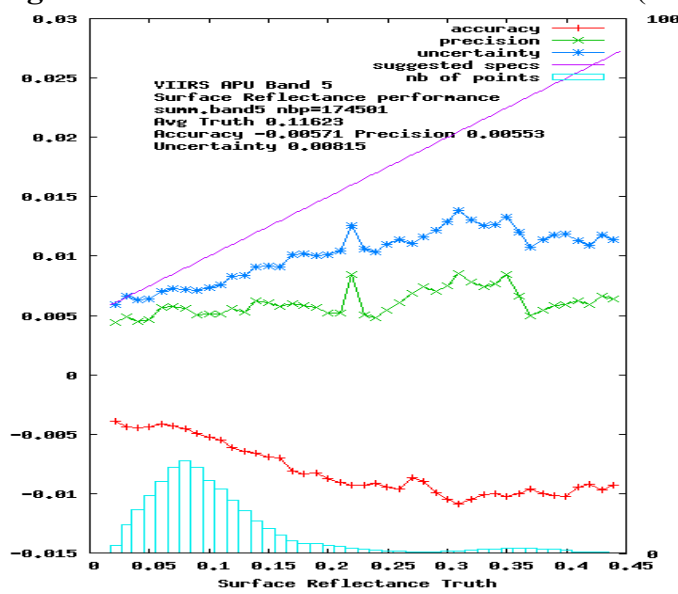

Figure 2f: same as 2a but for VIIRS (LaSRC).

\section{CONCLUSIONS}

This paper described a generic approach for atmospheric correction that uses the latest development in the state of the art of atmospheric correction, is traceable and associated with a strong validation background (NASA EOS heritage). The results presented clearly show a step forward between surface reflectance product from this algorithm (LANDSAT/OLI, MODIS collection 6) and the its precursor (MODIS Collection 5, LANDSAT/LEDAPS). Indubitably, this effort will be a corner-stone in a series of science products from a variety of sensors.

\section{REFERENCES}

[1] Holben, B.N., Eck, T.F., Slutsker, I., Tanre, D., Buis, J.P., Setzer, A., Vermote, E., Reagan, J.A., Kaufman, Y.J., Nakajima, T. and Lavenu, F., 1998. AERONET-A federated instrument network and data archive for aerosol characterization. Remote sensing of environment, 66(1), pp.1-16.

[2] Vermote, E.F., Tanré, D., Deuzé, J.L., Herman, M. and Morcette, J.J., 1997. Second simulation of the satellite signal in the solar spectrum, 6S: An overview. Geoscience and Remote Sensing, IEEE Transactions on, 35(3), pp.675686.

[3] S. Y. Kotchenova, E. F. Vermote, R. Matarrese, \& F. Klemm, 2006. Validation of a new vector version of the $6 \mathrm{~S}$ radiative transfer code for atmospheric correction of MODIS data: Part I - Path Radiance, Applied Optics, Vol 45., No. 26, 6762-6774.

[4] Gao, B.C. and Kaufman, Y.J., 2003. Water vapor retrievals using Moderate Resolution Imaging Spectroradiometer (MODIS) near-infrared channels. Journal of Geophysical Research: Atmospheres (19842012), 108(D13).

[5] Kaufman, Y.J., Tanré, D., Remer, L.A., Vermote, E.F., Chu, A. and Holben, B.N., 1997. Operational remote sensing of tropospheric aerosol over land from EOS moderate resolution imaging spectroradiometer. Journal of Geophysical Research: Atmospheres (1984-2012), 102(D14), pp.17051-17067.

[6] Levy, R.C., Remer, L., Mattoo, S., Vermote, E. and Kaufman, Y.J., 2007. Second-generation algorithm for retrieving aerosol properties over land from MODIS spectral reflectance. J. Geophys. Res, 112(D13), p.D13.

[7] Vermote, E.F. and Saleous, M.N., 2006. Operational atmospheric correction of MODIS visible to middle infrared land surface data in the case of an infinite Lambertian target. In Earth Science Satellite Remote Sensing (pp. 123-153). Springer Berlin Heidelberg.

[8] Vermote, E.F. and Kotchenova, S., 2008. Atmospheric correction for the monitoring of land surfaces. Journal of Geophysical Research: Atmospheres (1984-2012), 113(D23).

[9] Kotchenova, S.Y., Vermote, E.F., Levy, R. and Lyapustin, A., 2008. Radiative transfer codes for atmospheric correction and aerosol retrieval: intercomparison study. Applied Optics, 47(13), pp.22152226.

[10] Kotchenova, S.Y. and Vermote, E.F., 2007. Validation of a vector version of the $6 \mathrm{~S}$ radiative transfer code for atmospheric correction of satellite data. Part II. Homogeneous Lambertian and anisotropic surfaces. Applied optics, 46(20), pp.4455-4464. 